Cuadernos de Filología Clásica. Estudios Latinos ISSN: 1131-9062

http://dx.doi.org/10.5209/rev_CFCL.2016.v36.n2.54275

\title{
De la letra a la tela (II): Jan Steen y La enferma de amor en la pintura holandesa del Siglo de Oro a la luz de la tradición clásica ${ }^{1}$
}

\author{
Manuel Antonio Díaz Gito ${ }^{2}$
}

Recibido: 10 de diciembre de 2015 / Aceptado: 17 de marzo de 2016

Resumen. Última parte de las dos que componen un trabajo que se ocupa de analizar la influencia de la tradición clásica en un tema pictórico de gran predicamento entre los grandes maestros del Siglo de Oro de la pintura holandesa, La enferma de amor o La visita del médico, con especial atención a su tratamiento en la obra de uno de sus más conspicuos representantes, el pintor de Leiden Jan Steen (1626-1679).

Palabras clave: Tradición clásica; pintura holandesa del s. XVII; Jan Steen; La enferma de amor; La visita del médico.

\section{[en] Jan Steen and The lovesick maiden: Classical Tradition in Golden Age Dutch painting ( $2^{\text {nd }}$ Part)}

\begin{abstract}
Second one of a two-part analysis on the influence of the Classical Tradition on a favourite theme along the Dutch painters of the Golden Age, The lovesick maiden or The doctor's visit, especially in the Leiden artist's production, Jan Steen (1626-1679).

Keywords: Classical tradition; Seventeenth century Dutch painting; Jan Steen; The lovesick maiden; The doctor's visit.
\end{abstract}

Sumario. 1. Introducción. 2. Si populus uult decipi, decipiatur [«Si la gente quiere ser engañada, allá ella»] (Thomas Brian). 3. Una dama en apuros. 4. Clauis interpretandi: el cuadro-dentro-del-cuadro. 5. De la letra a la tela: conclusiones. 6. Referencias bibliográficas.

Cómo citar: Díaz Gito, M.A., «De la letra a la tela (II): Jan Steen y La enferma de amor en la pintura holandesa del Siglo de Oro a la luz de la tradición clásica», Cuad. filol. clás. Estud. lat. 36.2 (2016), 311-331.

1 Con el título de «De la letra a la tela (I): Jan Steen y La visita del médico en la pintura holandesa del Siglo de Oro a la luz de la tradición clásica», la primera parte de este trabajo se publicó en el anterior número de esta misma revista, Cuadernos de Filología Clásica. Estudios Latinos 36(1) (2016), 121-142. Uno y otro artículo se han beneficiado de la financiación del Proyecto de Investigación FFI2015-64490-P de la DGICYT y de la Red Internacional de Excelencia FFI2015-69200-REDT.

2 Universidad de Cádiz (España).

E-mail: manuel.diazgito@uca.es 
Ei mihi, quod nullis amor est sanabilis herbis nec prosunt domino, quae prosunt omnibus, artes!

Apolo a Dafne, Ov.Met.1.523-524

\section{Introducción}

En la primera parte de este trabajo abordé, desde el punto de vista literario y, en menor medida, de la tradición médica, un par de ideas preconcebidas que, desde la Antigüedad y a través de los cauces de transmisión del legado clásico, habían logrado llegar prácticamente ilesas hasta las postrimerías del siglo XIX: me refiero a la concepción del amor como una grave enfermedad, que afectaba con especial virulencia al género femenino, considerado este (y esta es la segunda idea) un sexo por naturaleza débil y propenso e indefenso ante la infección amorosa. Estos dos prejuicios, perpetuados en gran parte por todo tipo de literatura (también por la literatura médica), hallaron acomodo en la singular categoría de escenas de género o de costumbres de la pintura holandesa del Siglo de Oro y una plasmación artística especialmente atractiva en la obra de sus grandes maestros barrocos. Muy llamativamente destaca este asunto en la producción de uno de ellos, el pintor de Leiden Jan Steen (1626-1679), quien con sutiles variaciones afrontó el tema de «la visita del médico» o «la enferma de amor» en casi una veintena de obras desde mediados del siglo XVII, siendo por algunos considerado el inventor de tan específico 'tópos' pictórico. Tras esta necesaria contextualización, ya en la segunda mitad de aquel primer artículo, me detuve en analizar la influencia de la tradición clásica en el tratamiento de este asunto en la obra de Jan Steen, sirviéndome, a modo de cuadro-modelo, de una de sus mejores versiones del tema, La visita del médico, custodiada en el Metropolitan Museum of Art de Nueva York, que ahora debo reproducir de nuevo (Fig.1).

Además del escenario 'dramático' general y la utilería habitual con que se lo suele aderezar, empecé entonces por analizar el cuestionable retrato del personaje del médico, el protagonista masculino de este tipo de óleos, que se revelaba con sus tics característicos como una figura claramente heredera de la Comedia antigua y de todas sus continuadoras hasta la época del pintor.

Ahora, en esta segunda parte de mi trabajo, me propongo continuar analizando este lienzo del Metropolitan Museum, al que por las necesidades del desarrollo de la exposición sumaré otras imágenes similares o relacionadas. En primer lugar, para terminar con el análisis de la figura del médico, comento los obsoletos métodos diagnósticos que estos engolados doctores solían poner en práctica en medio de un gran aparato escénico. Me ocuparé, a renglón seguido, de la gran protagonista en torno a la cual todo evoluciona, la presunta enferma de amor, quien, en más de una ocasión, se revelará como una dama en graves apuros conyugales. Pero sobre todo intentaré aportar las claues interpretandi que a partir de la tradición clásica permiten profundizar en la mejor intelección de este tipo de obras, examinando de qué variados modos logran inmiscuirse textos, temas y tópicos de la literatura antigua en la superficie del cuadro ${ }^{3}$.

Tras el último epígrafe con las conclusiones finales de este estudio, aún se podría examinar un grupo particular de este tipo de obras en el que Steen, como si previera la paulatina pérdida de las necesarias referencias por efecto del paso del tiempo, se las arregla para incluir en ellas un revelador texto -una carta, un papel- con la 


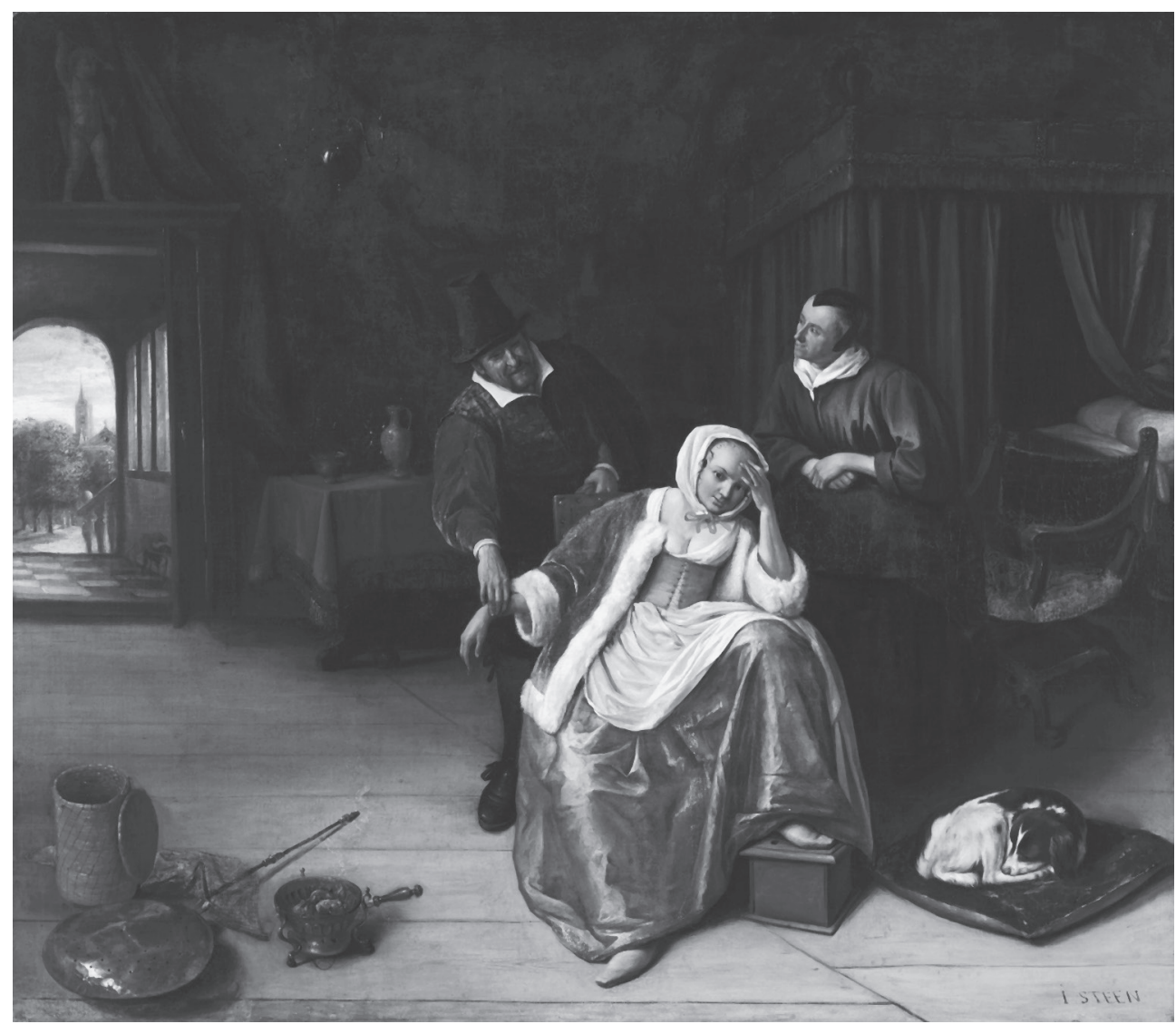

Fig. 1. La muchacha enferma de amor (ca. 1660), Jan Steen.

The Metropolitan Museum of Art, Nueva York

\section{Si populus uult decipi, decipiatur [«Si la gente quiere ser engañada, allá ella»] (Thomas Brian)}

En los cuadros de asunto médico de los pintores holandeses del siglo XVII encontramos plasmada toda una variada serie de prácticas diagnósticas y terapéuticas que ilustran fidedignamente el ejercicio de la medicina coetánea, pero dos de ellas, ancladas en la praxis médica de la Antigüedad, son las más reiteradas y caracterizadoras: el análisis del pulso y la observación de la orina del paciente en un recipiente de cristal o mátula. Mediante el desempeño de cualquiera de estas dos prácticas (o con ambas, como ya vimos en la figura del Cupidus medicus y en algún que otro médico de Jan Steen, $c f$. Fig. 4 y Fig.5 de la primera parte de este estudio), queda inequívoca-

función de desentrañar con seguridad las intenciones que esconde la estampa escenificada. Será esta una tarea que por razones de espacio reservo para otra ocasión ( $c f$. «Escrito en el lienzo: la tradición clásica y el billete de amor en La enferma de amor de Jan Steen, pintor holandés del Siglo de Oro», en curso de redacción). 


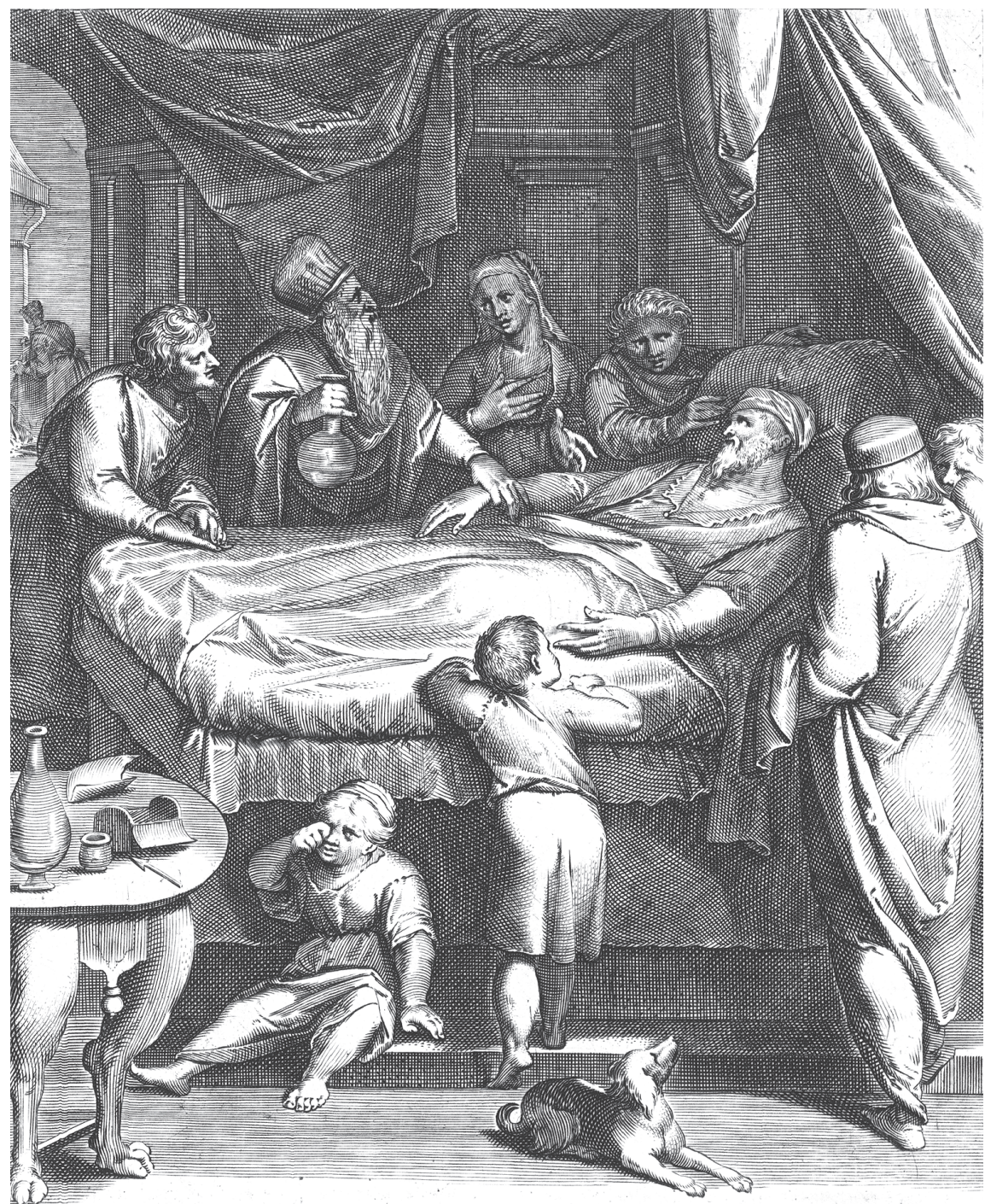

Fig. 2. Emblema 56 de Q. Horatii F. Emblemata (Amberes, 1612) de Otho Vaenius

mente identificado el personaje del médico; así también lo vemos, en pleno ejercicio de sus dos actividades características, en la siguiente estampa (Fig.2).

Desde la Edad Media, la uroscopia, un cuestionable método diagnóstico a través del examen del color, el olor y hasta el sabor de la orina del paciente, que, como mínimo, databa de las lecciones de Hipócrates, ya había desbancado al análisis del pulso como principal recurso para la detección de enfermedades, que, sin embargo, es lo que se representa mayoritariamente en los cuadros de médicos desfasados de Jan Steen. En menor medida, estas viñetas médicas de la pintura holandesa recogen también, con intención de variatio, otras prácticas terapéuticas, como la administración de un enema con una gran jeringa que sostiene con actitud burlonamente amenazante uno de los personajes (en Steen, como no podía ser de otra manera, con una obvia 
sugerencia fálica relacionada con las farsas cómicas: Dixon 1993, 28-35), o, todavía más esporádicamente (y nunca en la obra de Jan Steen), la sangría o el pediluvio.

De nuevo, la mordaz crítica de Quevedo nos viene al caso para ilustrar en un gracioso resumen las especiosas prácticas de los médicos del momento:

[...] La ciencia es esta: dos refranes para entrar en casa [...]; venga el pulso; inclinar el oído; $[\ldots]$ recetar lamedores, jarabes y purgas; [...] sangrarle y echarle ventosas; y hecho esto una vez, si durare la enfermedad, tornarlo a hacer hasta que, o acabes con el enfermo o con la enfermedad [...]. Si vive y te paga, di que llegó tu hora; y si muere, di que llegó la suya. Pide orines, haz grandes meneos, míralos a lo claro y tuerce la boca $[\ldots]^{4}$

Pero los exámenes de orina practicados por toda suerte de profesionales y pseudoprofesionales de la medicina se hicieron tan generalizados y los excesos en sus conclusiones llegaron a tal extremo que empezaron a dejarse oír, ya desde el siglo XVI, voces ferozmente críticas con el tradicional método. Se editan obras de asunto médico que denuncian virulentamente la falta de fiabilidad, cuando no el disimulado engaño, del examen uroscópico. De ellas, a modo de ejemplos, citaré dos: no son las primeras, pero sí bastante representativas del grado de abuso alcanzado ${ }^{5}$. Bajo el beligerante lema de Si populus vult decipi, decipiatur («Si la gente quiere ser engañada, allá ella») el británico Thomas Brian en 1637 había puesto en solfa la práctica de la uroscopia en un libelo titulado con sarcástica intención The Pisse-Prophet. Un fragmento de otra obra menos conocida, aparecida el año siguiente en tierras alemanas, también describe la estudiadísima puesta en escena, tan teatralizada como en los cuadros holandeses, de estos descarados 'urinomantes':

[...] Se sirven de todo tipo de estrafalarios gestos, sostienen la mátula con la orina contra un espejo, la miden con un compás, deambulan arriba y abajo, adelante y atrás, a un lado y a otro de la estancia, la agitan y la hacen sonar, vuelcan y hacen girar el pis (perdonen mi francés) en el cristal, vierten unas gotas en el suelo, sopesan el recipiente en sus manos, olisquean la orina -y sí, incluso la degustan ( $\sin$ duda, el moscatel que se merecen)-, sostienen la mátula contra un foco de luz o en dirección al sol a pleno día, destilan o tamizan la orina, y cualquier otra innecesaria monería, payasada y bufonería estos embaucadores podrían usar para crear expectación, atraer a la gente y arrebatarles una bonita suma de dinero. [...] (Ludwig von Hörnigk, Politia medica, 1638, fol.177) ${ }^{6}$

$4 \quad$ F. Quevedo, Libro de todas las cosas y otras muchas más, 1627. He consultado la edición de la Biblioteca Clásica Española de 1884: el texto de arriba aparece en la p.262. Ya me serví de otro pasaje del mismo texto en la primera parte de este trabajo (Díaz Gito 2016, 138).

5 Un ilustre precedente en los Países Bajos de esta corriente crítica fue el médico oficial de la ciudad de Delft, Pieter van Foreest (1521-1597), el 'Hipócrates holandés', que ya en 1589 tronó contra los farsantes examinadores de orina en De incerto, fallaci Urinarum judicio quod Uromantes ad perniciem multorum aegrotantium utuntur... libri tres, per dialogismum contra Uroscopos concinnati, reeditados y traducidos al neerlandés y al inglés a principios del s. XVII. Unos años antes, en 1584, editaba el médico y filósofo alemán Wilhelm Adolph Scrobonius (1550-1600) un tratado similar De inspectione urinarum contra eos, qui ex qualibet urina de quolibet morbo judicare uolunt etc.

6 El texto es un fragmento de Politia medica (Frankfurt, 1638) del alemán Ludwig von Hörnigk (1600-1667), que he traducido de una versión inglesa del pasaje ( $c f$. https://praeludiamicrocosmica.wordpress.com/2013/07/10/ an-abc-of-shady-figures-on-the-early-modern-medical-marketplace/ [21/03/2016]). 
En definitiva, a tenor de estos testimonios, cabe deducir que la escena representada en este tipo de cuadros, tanto si el doctor toma el pulso, como sobre todo si ojea el contenido de la mátula, delata una vez más lo cuestionable que resultaban los conocimientos médicos del viejo galeno.

Destaca, además, un elemento casi inevitable en este tipo de cuadros de Steen que, sin embargo, no se encuentra en los otros grandes maestros de su época y cuya función y utilidad desde la óptica actual se resiste a ser desentrañada con certeza (Stolberg 2015, 109-110). Con frecuencia, en un brasero a los pies de la joven alicaída se ha puesto a arder una cinta ( $c f$. infra Fig.3 y Fig.7). Pues bien, desde principios del siglo XX se ha extendido la idea de que se trataba de una peculiar prueba diagnóstica de embarazo: al parecer, se creía popularmente que, si con el olor que desprendía la cinta quemada, previamente impregnada con la orina de la enferma, la condición de esta empeoraba sensiblemente -sentía náuseas, sufría un desvanecimiento- era indicio de que se hallaba encinta. De ser esto así, en la lógica de la secuencia dramática, la realización de este extravagante test de embarazo debe ser anterior al recurso del médico, que es llamado bien para confirmar resignadamente el resultado positivo de la prueba, bien con la esperanza de que la ciencia médica supuestamente superior que él encarna abra una vía de escapatoria a la atribulada dama. E independientemente de su resultado, el hecho de que se hubiera efectuado la prueba sería ya de por sí señal de que la relación sexual o, en su caso, el adulterio, se había consumado: la cinta, como una evidencia criminal, se halla en el suelo a la vista de todos (a veces, se retuerce como una serpiente evocadora del pecado original). Siguiendo con esta hipótesis, se arguye que, en ocasiones, se puede adivinar el resultado positivo del test y las nada halagüeñas consecuencias que acarreará: o un personaje secundario sostiene entre lágrimas la cinta en sus manos, o la mujer ha sufrido un súbito desmayo o el perro faldero, símbolo de fidelidad conyugal, husmea el trozo de tela con sospecha (este último detalle indicaría que, desde luego, el olor es el factor clave en el uso de estos hornillos). Pero quienes niegan por falta de evidencia esta tan divulgada explicación (así Dixon 1995, 143-145) alternativamente ofrecen otras plausibles soluciones para explicar la omnipresencia del brasero y la cinta quemada en los cuadros de Steen: a saber, que, como instrumentos de una terapia basada en el olor, o bien podía servir como un medio de hacer volver en sí a una mujer desmayada, o bien para la reubicación de un 'útero viajero' (esta última es la interpretación preferida por Dixon 1995, 145-147 - cf. et Dixon 2015-, y por Lubsen-Brandsma 1997).

Pero en mi opinión, hay un argumento en contra de vincular el uso de estos hornillos con la praxis médica del doctor presente en la escena. Al menos en un par de versiones de la entrevista médica de Steen el médico, según parece recién llegado a la casa, ha tomado asiento y está siendo agasajado con una copa de bienvenida por la criada antes de desplegar sus conocimientos médicos: la presencia del hornillo con la cinta quemada parece ser, pues, anterior y, sobre todo ajena, al ejercicio de la actividad del doctor?

Sea como fuere, la alusión a un posible embarazo de la dama del cuadro sigue estando sugerida suficientemente por otros detalles de la escena ${ }^{8}$, el principal de

$C f$. la obra de Steen a la que remitimos en nota 23 .

8 En una obra de Steen protagonizada por una de estas enfermas, un lienzo perdido pero descrito en 1926 por C. Hofstede de Groot, figuraría una nota escrita advirtiendo «Si no me equivoco, esta chica trae niño»: para sostener su propia interpretación, Dixon se ve obligada a restar validez a esta información por su imposible verifica- 
los cuales sería la propia presencia del médico examinando la orina de la mujer: la escasa fiabilidad de la uroscopia como método diagnóstico de embarazo, uno de los temas denunciados por los debeladores de los 'urinomantes' o 'pissprophets', es prueba de lo extendido del recurso a estos examinadores de la orina para confirmar o descartar un posible embarazo 9 .

\section{Una dama en apuros}

La coprotagonista del cuadro de asunto médico es, claro está, la enferma. Una dama burguesa, ataviada con gran elegancia como índice de su estatus económico y social, recibe la visita masculina del doctor. Por lo general, atiende al médico sentada lánguidamente en un sillón con la cabeza apoyada en la mano en actitud estudiadamente melancólica. Me refiero a la postura estereotipada con que se representaba la alegoría de la Melancholia desde época medieval -y que recoge, entre otros, la célebre estampa de Alberto Durero-, pero que también comparte la imagen de la Lujuria (Libidine) en la divulgadísima Iconologia (Roma, 1603, 294-295) de Cesare Ripa, de uso común entre los artistas plásticos de la época ${ }^{10}$. La descripción de Ripa de la Libidine es bastante parecida a la actitud de muchas 'enfermas de amor' de Jan Steen:

Donna lascivamente ornata, sedendo appoggiata sopra il gomito sinistro, nella mano destra terrà uno Scorpione, a canto vi sarà un Becco acceso alla Libidine et una vite con alcuni grappi d'Uva.

Y la explicación de tal postura es la siguiente: «Sta a sedere et appoggiata su'l braccio, per mostrare l'otio del quale si fomenta in gran parte la Libidine».

ción (Dixon 1995, p.143, n.27). Sin embargo, en otra versión de la «visita del médico» de Steen conservada en la Galería Nacional de Praga, la enferma a la que el doctor le extiende una receta está visiblemente en avanzado estado de gestación ( $c f$. https://commons.wikimedia.org/wiki/N\%C3\%A1rodn\%C3\%AD_galerie_v_Praze\#/media/File:Jan_Steen_-_Physician_and_a_Woman_Patient.JPG [23/03/2016]). Por otro lado, Gottfried Schalken (1643-1706), pintor holandés perteneciente a la generación siguiente a la de Steen, trabajaba en Leiden en la misma época que este y en una de sus obras debió de querer imitar su estilo y su temática de «la enferma de amor» solo que haciendo descaradamente obvios los elementos que en la obra del modelo, por lo general, lo son menos. En su interpretación de este tema, conocida como El examen del médico - que, con toda propiedad, hacía pendant con una obra alegórica sobre la pérdida de la virginidad (Una lección inútil), conservadas ambas en el Mauritshuis Museum de La Haya-, la muchacha llora por lo irremediable de su caso ante el gesto malhumorado de su padre, mientras que un niño, divertido, hace un gesto obsceno con la mano y sobre la mesa descansa una jeringa sugerentemente fálica: aquí no hay cabida para la duda porque el médico en la mátula observa con atención ¡un minúsculo feto flotando en la orina! ( $c f$. http://www.mauritshuis.nl/en/explore/the-collection/artworks/ the-doctors-examination-161/\# [23/03/2016]).

9 En una obra recién aparecida, que lamentablemente solo he podido manejar en parte a través de la red, Uroscopy in Early Modern Europe (Surrey, Ashgate, 2015), su autor Michael Stolberg dedica un apartado a «Diagnosing Pregnancy» bajo el epígrafe «Uroscopy and Popular Culture». Por otro lado, Stolberg cita un trabajo previo (p.109, n.20) donde apuntaba otra posible explicación al uso de estos hornillos: el olor que desprendían sería usado como una pista para el diagnóstico del embarazo.

10 Recordemos que ya desde el propio subtítulo de la obra se indica la finalidad ancilar que Ripa quiso conferirle, Iconologia overo descrittione dell 'imagini universali cavate dall'antichità et da altri luoghi da Cesare Ripa perugino. Opera non meno utile, che necessaria à poeti, pittori, \& scultori, per rappresentare le virtù, vitii, affetti, \& passioni humane. La princeps había aparecido en 1593 sin imágenes, pero a partir del éxito de esta edición de 1603 ampliada y ya ilustrada, se volvería a imprimir en numerosas ocasiones sucesivamente ampliada, tanto en el número de voces como en el de estampas, así como traducida a varios idiomas. 


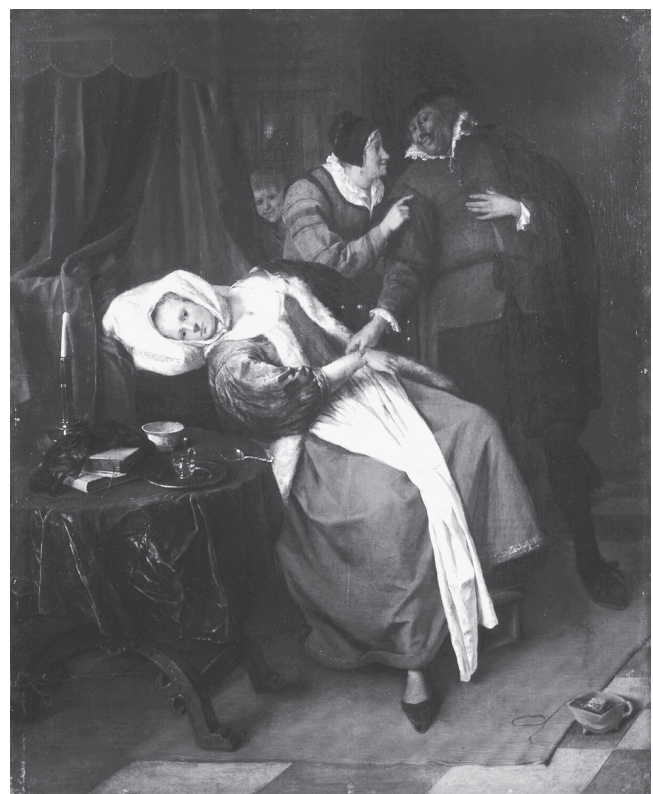

Fig. 3. La visita del médico (ca. 1660), Jan Steen. State Hermitage Museum, San Petersburgo

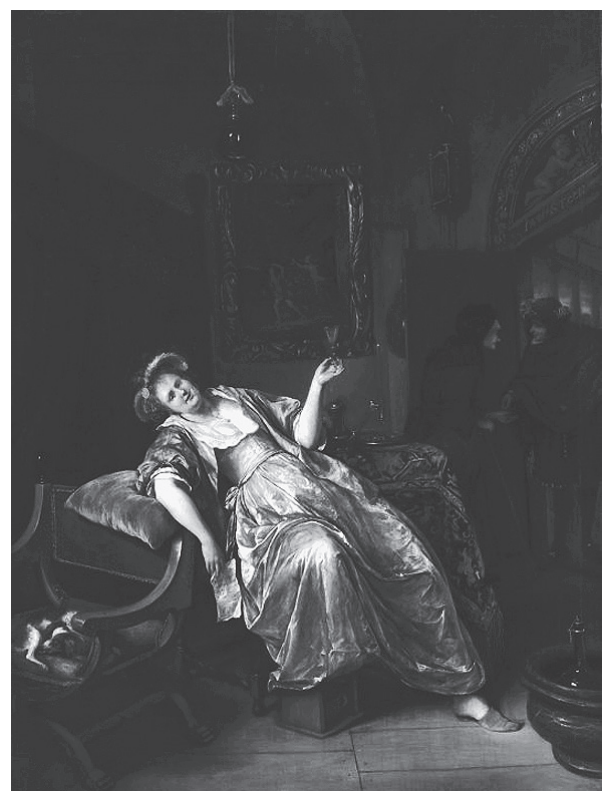

Fig. 4. La borracha (ca. 1665-1668), Jan Steen. Museum of Fine Arts, Budapest

Con mucha frecuencia su cuerpo adopta en el sillón una postura poco decorosa, bastante explícita, que deja poco lugar a la imaginación acerca de dónde se ubica el origen de su mal (furor uterinus). A este respecto conviene observar la similitud de su pose, tan inadecuada para una dama burguesa (Fig.3), con la que adopta la protagonista, una prostituta ebria, del cuadro de Jan Steen titulado La borracha (¿ $L a$ alcahueta?) (Fig.4) ${ }^{11}$.

En alguna que otra ocasión, se acentúa la gravedad del caso de la enferma haciendo que reciba al médico acostada en la cama ( $c f$. Fig.4 de la primera parte, el emblema 85, Amans amanti medicus de Amorum emblemata (1608) de O. Vaenius). Una cama que es lecho donde yace la enferma y lecho donde ha retozado la enamorada. Se atisban dos tipos de situaciones. O se trata de una enferma de amor (técnicamente en la época se hablaba de pacientes de febris amatoria, morbus virgineus o chlorosis). $\mathrm{O}$ se trata de una adúltera consumada. En ambos casos, para empeorar las cosas, aletea en el ambiente la posibilidad de un inoportuno embarazo, como acabo de apuntar.

La gestualidad de la dama evoca un amplio espectro de emociones que van desde la ansiedad a la desesperación o la resignación. La mujer parece debatirse entre la certeza de la naturaleza de su mal, al que juzga irremediable, y la vana esperanza de que el dictamen del médico, al que quizás ha recurrido como última baza, revele infundadas sus peores sospechas. Una de estas enfermas, en Frans van Mieris, recibe las aten-

11 Otras mujeres embriagadas en similares posturas indecorosas ocupan el centro de otras obras de Steen como Noche de Reyes (1668), en el Staatlische Mussen Kassel (http://www.museum-kassel.de/index_navi. php?parent=1497 [21/03/2016]), o El hogar disoluto (ca. 1665), en The Metropolitan Museum of Art, Nueva York (https://www.metmuseum.org/toah/works-of-art/1982.60.31/ [21/03/2016]). 

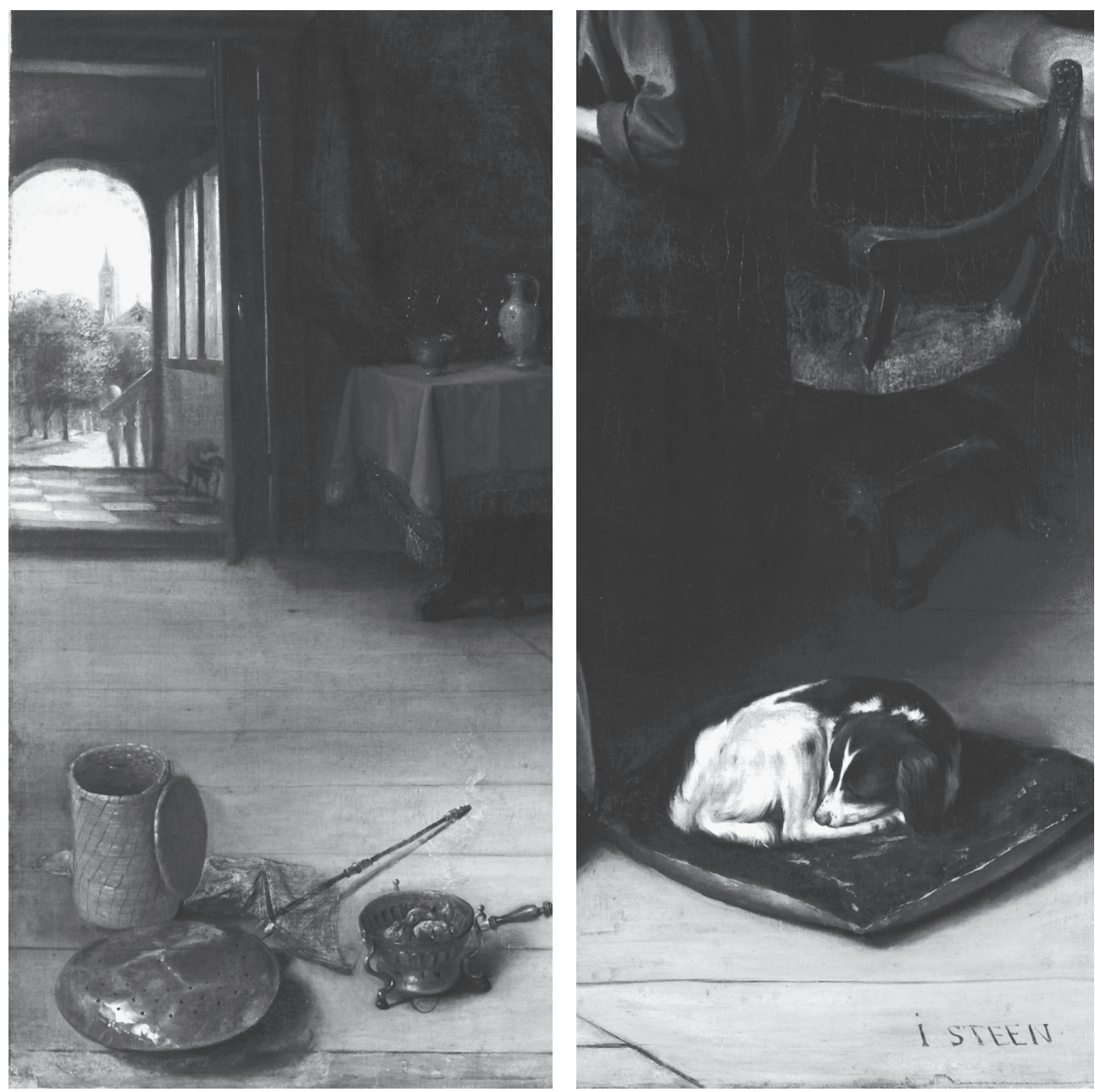

Fig. 5 y fig. 6. Detalles de Fig.1, La muchacha enferma de amor (ca. 1660), Jan Steen, The Metropolitan Museum of Art, Nueva York

ciones del médico mientras sostiene sobre su regazo la Biblia abierta por el Nuevo Testamento, en un acto, quizás desesperado y demasiado tardío, de contrición ${ }^{12}$.

Por último, la índole sexual y animalesca de la patología que arrastra a la mujer a la urgencia del coito, aun a riesgo de la ruina de su familia, aparece en el cuadro del Metropolitan glosada por Steen con la más descarnada de las evidencias: la difusa imagen al fondo, en el corredor que conduce a la puerta de salida, de dos perros copulando, poseídos por el degradante amor ferinus o bestialis y convenientemente alineados con los objetos caloríficos (el brasero, el calientacamas) (Fig.5), parafrasea gráficamente el furor uterinus que sufre la joven (motivo presente, con idéntica

$12 C f$. Frans van Mieris, el Viejo, La visita del médico, 1657, en Kunsthistorisches Museum, Viena ( $c f$. http:// bilddatenbank.khm.at/viewArtefact?id=1221 [21/03/2016]). 
intención, en una escena de burdel de Fran van Mieris $\left.{ }^{13}\right)$. La cópula de los perros debe ser un símbolo sinónimo del macho cabrío que como animal-atributo acompaña a la figura alegórica de la Libidine de Cesare Ripa que he citado antes, significando que «s'intende il Becco per la Libidine, essendo ne gli atti di Venere molto potente et dedito a tal inclinatione soverchiamente» (Ripa 1603, p.295): en alguna atrevida traducción inglesa de la obra de Ripa la imagen de Lust muestra al macho cabrío lascivamente montado sobre la pierna de la joven. Frente a estos canes acuciados por el instinto, contrasta la imagen en primer plano -y en el otro lado, el de la cama matrimonial-, de otro perro, típico símbolo de fidelidad conyugal ${ }^{14}$, durmiendo plácidamente sobre un cojín, en exceso despreocupado y confiado en la lealtad de su dueña (Fig.6), quizás como el propio marido de la mujer. Sobre el personaje de la dama, tendré que volver más tarde.

Entre los personajes secundarios, sólo pasaré de puntillas por el de la criada, que hace las veces de cuidadora/enfermera, atenta a las explicaciones y gestos del médico, preocupada por la salud de su dueña; en ocasiones, desde el umbral de la puerta de entrada a la casa, actúa como la clásica medianera entre la señora y su amante, a modo de cómplice y alcahueta, función esta que deriva de su rol habitual en la tradición de la literatura clásica (el drama, la novela antigua, etc).

\section{Clauis interpretandi: el cuadro-dentro-del-cuadro}

Mucho más relevante desde la perspectiva de la tradición clásica me parece una técnica narrativa usada en muchas ocasiones por los pintores flamencos en sus escenas de interior. Sobre la pared, cuelga un cuadro. Es la conocida técnica del cuadro-dentro-del-cuadro, que opera como clauis interpretandi del tema general representado. En «la visita del médico», el drama de la protagonista se refleja, como en un espejo, desde el cuadro-dentro-del-cuadro que pende de la pared: suele ser este de asunto mitológico y erótico, donde frecuentemente dos amantes retozan entre la verde espesura de un locus amoenus.

Jan Steen emplea esta técnica en otra magistral versión de La visita del médico (1658-1662), la del Wellington Museum de Londres (Fig.7).

Dejando momentáneamente a un lado los tres personajes habituales, centremos ahora la atención en las principales novedades respecto de la versión modélica previamente analizada. Hay dos figurantes nuevos. Reemplazando a la estatuilla de Cupido presente en otras ocasiones, ahora un niño, sentado en el suelo en primer plano, juega con un arco y unas flechas. Y en la estancia del fondo a la izquierda, se atisba un señor de cierta edad, enfrascado en la lectura de un documento. ¿Quiénes son estos nuevos personajes? Parece evidente que el crío juguetón debe ser un hijo de la dama enferma. Pero, ¿y el señor del fondo? ¿es el padre de la dama? ¿o el ‘clásico’ marido demasiado viejo para su joven esposa ${ }^{15}$ ? (Recordemos el epigrama

$13 C f$. Frans van Mieris, el Viejo, Escena de taberna o de burdel, 1658, en el Mauritshuis, La Haya (cf. http://www. mauritshuis.nl/en/explore/the-collection/artworks/brothel-scene-860/ [21/03/2016]). Sobre este tercer concepto de 'amor', opuesto tanto al amor diuinus como al amor humanus, y su jerarquización en la filosofía neoplatónica sobre el amor del Renacimiento (Marsilio Ficino, Pico della Mirandola), cf. Panofsky 1969, 117-119.

14 Cf. infra el texto al que hace referencia la nota 16.

15 Apuestan por identificar al señor con el padre de la dama A.K. Wheelock, Jr., y M. Westermann, según Franits, mientras que él mismo se decanta por ver en él al viejo esposo de la joven mujer (Franits 2004, p.293, n.22). 


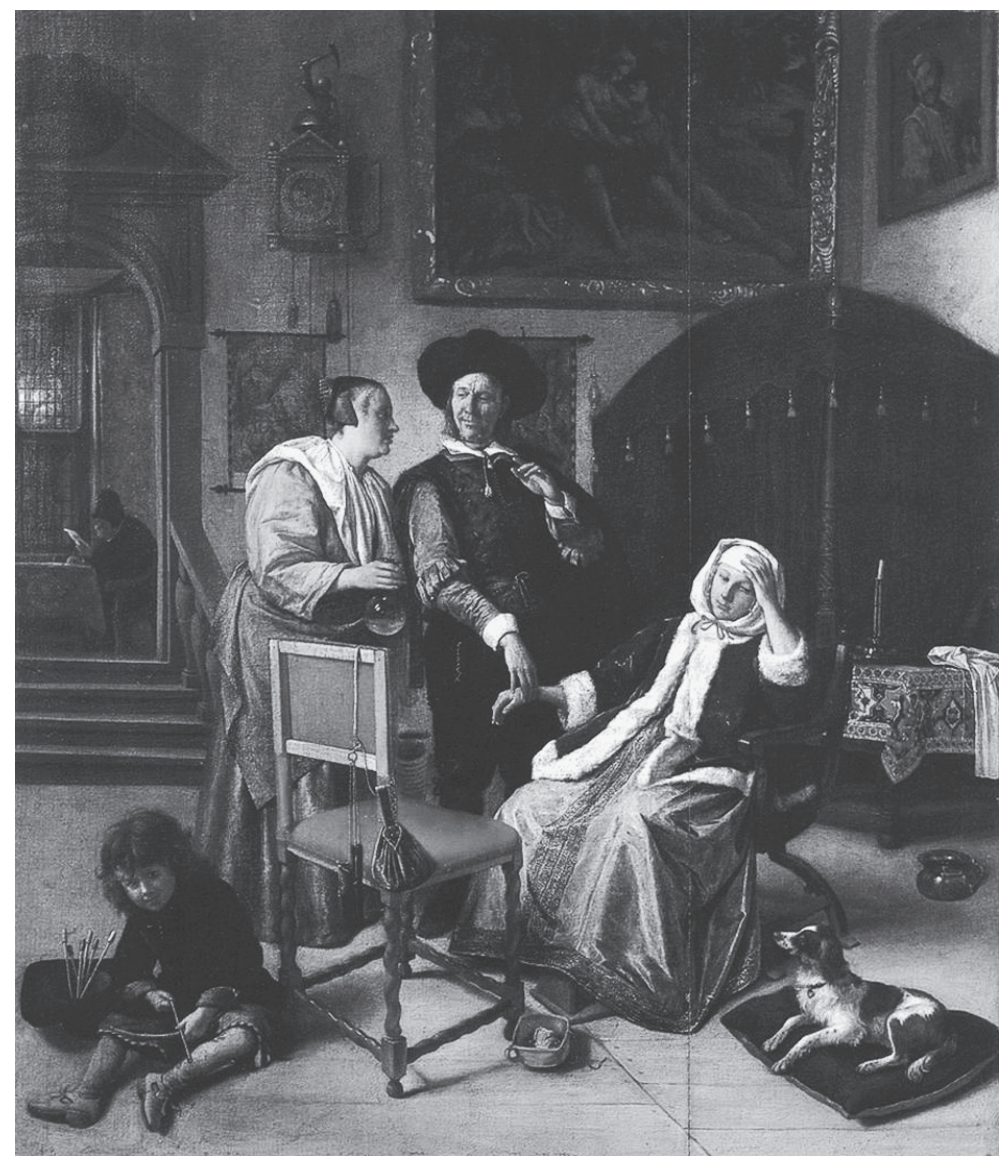

Fig. 7. La visita del médico (1658-1662), Jan Steen.

Wellington Museum, Apsley House, Londres

de Marcial, MART.11.71, que cité en la primera parte del trabajo, $c f$. Díaz Gito 2016, 127). Prominentemente situada casi en el centro del cuadro y enfrentada a la enferma de amor, una silla vacía evoca la ausencia del amante, única idea que ocupa la mente febril de la joven, que calibra su calentura con el ademán de llevar la mano a la sien. De la silla penden las llaves y el bolso de la dama, símbolos de su posición de dominio en la casa: la mujer, como las heroínas de la Antigüedad-Medea, Fedra-, se halla en el dilema de sopesar y elegir entre lo que le dicta la razón y aquello hacia lo que la empuja el deseo, aun a sabiendas del peligro que entraña para el bienestar de su casa. Un perro, con un collar del que pende un colgante en forma de corazón (¿un regalo del marido?), descansa, pero alerta ante la situación, sobre un cojín al lado de su dueña. Hay que notar que la alegoría de la Fidelidad (Fedeltà) en la Iconologia (153-154) de Cesare Ripa se define por la presencia simbólica de un perro ${ }^{16}$ junto

16 También figura un perro a los pies de un matrimonio con las diestras unidas (y un manzano con los frutos de Venus a su izquierda) en la pictura que ilumina la inscriptio «In fidem uxoriam», la CXCI del Liber emblematum de Alciato (Augsburgo, 1531, f.D 2 ), una de las fuentes de Ripa. El epigrama comienza así: Ecce puella, uiro quae 
a la figura de una mujer que porta una llave (también un anillo en otras estampas): en el cuadro de Steen, parece que estos objetos icónicos de la autoridad doméstica femenina, la llave y el bolso, pendientes del espaldar de la silla, quieran evidenciar el inestable equilibrio por el que atraviesa la situación familiar.

Dejando a un lado el simbólico reloj, ya comentado en la primera parte de este estudio, me referiré ahora a los cuadros que cuelgan de las paredes. El cuadro-dentrodel-cuadro es un recurso pictórico paralelo a la técnica poética del relato-dentro-delrelato que caracteriza al epyllion alejandrino-helenístico (Crump 1931; Hollis 2006; Hunter 2004; Baumbach - Bär, 2012) y que en la literatura latina Ovidio (Barchesi 2002), después de las experiencias neotéricas de Catulo (Sklenáŕ 2006) y de Virgilio (Owen Lee 1996, esp. 101-126), llevó al límite de sus posibilidades artísticas en el complejo armazón compositivo de las Metamorfosis. En el empleo de esta técnica compositiva pictórica, la 'escritura' figurativa converge con la escritura textual. No puede dejar de ser relacionada asimismo con otra técnica de amplísimo arraigo a partir de la literatura clásica, la ekphrasis, en la medida en que se reproduce dentro del cuadro un objeto artístico - esto es, otro cuadro- como medio de iluminar de un modo u otro el relato principal (sobre la écfrasis, Elsner 2002; Mesa Sanz 2010; y Agudelo 2011).

En el caso que nos ocupa, hay un cuadro claramente reconocible, el de la pared lateral: es del pintor holandés Frans Hals (1582/83-1666), titulado Peckled Herring (ca. 1615-1628), en los últimos años depositado en préstamo en el Museum Palace Wilhelmshöhe, de Kassel. Se dice que Frans Hals era uno de los pintores favoritos de Steen y que quizás este había adquirido esta obra o al menos había quedado prendado de ella, pues también aparece reproducida en otra de sus pinturas (El bautizo). El Peckled Herring -la traducción literal sería «Arenque en escabeche»- alude a un personaje-tipo cómico de la farsas populares, inclinado a la bebida y con ciertas connotaciones sexuales, que, como tal, también aparece en algún que otro cuadro de Steen, tan aficionado a las manifestaciones teatrales de todo rango. Se me ocurre que la función de la aparición indirecta de un 'Peckled Herring' en este cuadro podría ser la de sugerir la teatralidad cómica de lo escenificado, además de subrayar el carácter sexual de la situación representada ${ }^{17}$. O incluso podría pensarse en una suerte de 'autorretrato' por persona interpuesta - persona en el sentido dramatológico-: el gesto indulgente y humorístico de este bufón de las farsas contemporáneas congenia con la idiosincrasia del pintor tal y como se nos muestra a través del resto de su obra, como gusta de representarse a sí mismo en ella y como nos lo retratan las noticias de la época.

Pero el cuadro que me interesa más y que por su posición y tamaño y hasta por el lujoso marco se muestra claramente focalizado es el cuadro principal de la pared frontal, del que se ha dicho que representa a Venus y Adonis. Y así es, pues

dextra iungitur: ecce/ V[t] sedet, ut catulus lusitat ante pedes, / Haec fidei est species:... En muchas de las sucesivas ediciones del Emblematum liber, el perro tiende a ocupar una posición fija: como en los cuadros de Steen, a la derecha de la dama descansando o dormido (en la editio princeps de Alciato, sobre las faldas de su vestido).

17 Franits (2004, p.25) confirma el conocimiento que de este lienzo se tenía en la época al señalar que, todavía en vida de Hals, además de las copias del cuadro representadas en las dos obras aludidas de Steen, se usó la reproducción de este retrato en el frontispicio de un libro de chistes titulado Nugae Venales (Amsterdam, 1648), aparecido unos años antes que la obra de Steen comentada arriba: en este tipo de libros, por cierto, era habitual la burla indiscriminada de los médicos. Ignoro si Steen conocía este volumen y si, de ser así, pretendía con la inclusión en su obra de la figura cómica del 'Peckled Herring' restar importancia a la aparente seriedad de la escena representada o incluso acentuar la ridiculez de la actuación del médico. 


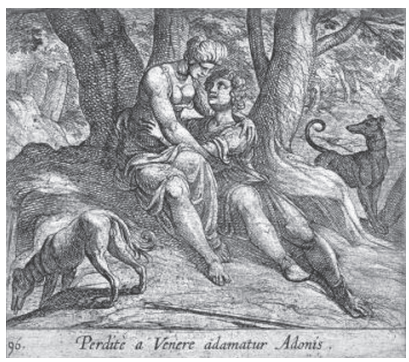

Fig. 8. Antoni Tempesta, Perdite a Venere adamatur Adonis [1606?]

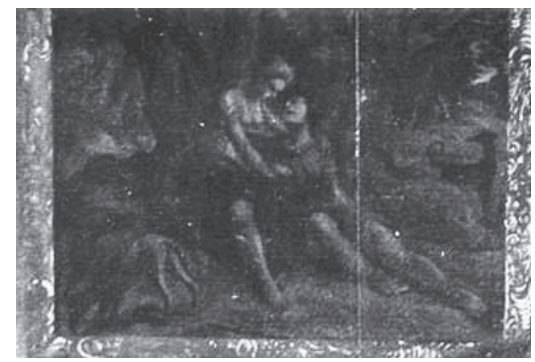

Fig. 9. Detalle de Fig.7, La visita del médico, J. Steen. Wellington Museum, Apsley House, Londres

se asemeja a óleos coetáneos como los de Joachim Wtewael o Hendrick Goltzius ${ }^{18}$, donde la pareja de enamorados del mito retoza en un idílico paraje a la sombra de un árbol. Pero Steen no se limita a recrear la típica escena mitológica a la manera de los compatriotas que lo precedieron, sino que, como en el caso del Peckled Herring de Frans Hals, reproduce intencionadamente una obra preexistente. La imagen que copia Steen en su cuadro es una de las ciento cincuenta estampas que el pintor y grabador florentino Antoni Tempesta (1555-1630) ideara para la edición ilustrada de las Metamorfosis de Ovidio impresa en Amsterdam probablemente en $1606^{19}$; la comparación de las dos obras (Fig.8 y Fig.9) no deja lugar a la duda ${ }^{20}$.

Este gesto deliberado por parte de Steen, además de que también podría refrendar una vez más el alcance de su educación humanista, sobre todo nos abre una nueva vía llena de sugerencias para alcanzar la plena intelección de la escena representada. La estampa de Tempesta (Perdite a Venere adamatur Adonis) ilustra un preciso pasaje de las Metamorfosis de Ovidio (Met.10.555-559):

opportuna sua blanditur populus umbra,

datque torum caespes: libet hac requiescere tecum

18 Cf. Venus y Adonis atribuido a Joachim Wtewael (1566-1638) en préstamo en el Liechtenstein Museum de Viena (cf. https://commons.wikimedia.org/wiki/File:\%27Venus_and_Adonis\%27_by_Joachim_Wtewael.jpg [21/03/2016]); o de Hendrick Goltzius (1558-1617), Venus y Adonis (1614) en el Bayreuth Palace, Bayreuth (cf. http://www.pinakothek.de/en/hendrick-goltzius/venus-and-adonis [21/03/2016]).

19 Se ha señalado la gran influencia de los grabados de Antoni Tempesta, reproducidos ampliamente en Francia y Países Bajos, en pintores de la talla de Guercino, Rubens o Velázquez, entre otros (a su muerte Rembrandt había reunido una colección de 200 grabados del italiano). En una obra poco posterior a la que comento arriba, Mujer que recibe una carta (ca. 1663-65) del pintor de Rotterdam Ludolf de Jong se emplea la misma técnica del cuadro-dentro-del-cuadro con otra de las estampas ovidianas de Tempesta, la que ilustra la historia de Diana y Acteón (Franits 2004, 194-195). La entrada correspondiente a «Tempesta (Antoine)» en El manuel de l'amateur d'estampes (París, 1821), del grabador F.E. Joubert, ocupa las pp.117-126 del vol. III, donde se cataloga las principales estampas de las más de dos mil que le atribuye al italiano, entre ellas las que hizo para las Metamorfosis ovidianas (en pp.123-124). Mucho más detallado, hasta 1460 piezas enumera Adam Barscht en el vol. XVII de Le peintre graveur (Vienne, 1818), pp.124-188 (en la p.151, la referencia a las estampas ovidianas). El título exacto de la obra en la que aparece el grabado que nos interesa es Metamorphoseon, Sive Transformationum Ovidianarum Libri Quindecim, Aeneis Formis ab Antonio Tempesta Florentino Incisi, et in Pictorum Antiquitatisque Studiosorum Gratiam Nunc Primum Exquisitissimis Sumptibus a Petro de Iode Antuerpiano in Lucem Editi. Amsterdam, [1606?].

20 Según noticia de Franits, Georg J.M. Weber ha sugerido un grabado de Maarten van Heemskerck (1498-1574) que no he podido localizar (Franits 2004, 293-294). 
(et requieuit) humo pressitque et gramen et ipsum

inque sinu iuuenis posita ceruice reclinis

sic ait ac mediis interserit oscula uerbis: ${ }^{21}$

Es importante que situemos en su contexto narrativo este pasaje. El libro décimo de las Metamorfosis de Ovidio está consagrado al discurso narrativo de Orfeo ${ }^{22}$. Tras recordar el desdichado destino de Eurídice, sigue el lamento del mítico cantor de Tracia, que, en duelo por la pérdida ya irremediable de su esposa, se consuela de su insondable tristeza con el bálsamo terapéutico de su propia música, cantándose a sí mismo una serie de diferentes relatos de amor (o epylliones, relatos-dentrodel-relato), entre los que, además del de Venus y Adonis, habría que destacar otros tres igualmente célebres, el de Pigmalión, bisabuelo de Mirra, la madre de Adonis; el relato incestuoso de Cíniras y Mirra, los padres de Adonis; y el de Atalanta e Hipómenes, que le cuenta Venus a su joven amante para intentar infructuosamente inculcarle el temor a las fieras (esta serie de relatos-dentro-del-relato ocupa las dos terceras partes del libro X de las Metamorfosis, desde el v.243 al v.739).

El mito de Pigmalión, el escultor que se enamoró de su propia obra de arte, junto al de Orfeo, el músico sublime por antonomasia - $\mathrm{u}$ otros similares, como el de Aracne-, encontraban singular estima entre los cultivadores de las distintas facetas del arte (escultura, música y poesía, el arte figurativo) por su potencialidad metaartística, es decir, por su capacidad de auto-reflexión sobre la naturaleza misma del fenómeno artístico: uno y otro no debieron de pasar desapercibidos a un pintor de elevada formación humanística como Steen.

Pero el relato ovidiano deliberadamente proyectado sobre la escena médica desde el lienzo colgado en la pared frontal de la estancia es el de los amores de Adonis y Venus (Ov.Met.10.519-559), oportuno en el contexto de la enferma de amor visitada por el médico porque sirve para ilustrar varios temas adecuados a su caso ${ }^{23}$. En primer lugar, este relato trata el tema de la juventud exuberante e irreflexiva que hace caso omiso de los consejos sensatos: Adonis no atiende la prudente advertencia de Venus de evitar los riesgos de la caza y, por ello, acabará víctima de las dentelladas de un jabalí (Met.10.519-739, esp.710-739). Esto es aplicable al juicio alocado de la joven víctima de la pasión erótica y a los riesgos de un embarazoso desenlace. El personaje de Adonis, además, evoca la historia de su madre Mirra, un caso que se

21 «(Habla Venus:) "este oportuno álamo nos invita con su sombra y un lecho nos ofrece el césped” -y, mientras se recostaba, añadía - "me apetece recostarme contigo en este lugar" y se acomodó sobre la hierba y sobre el joven y, tras colocar el cuello sobre el regazo de él, que la abrazaba, le dice así, mientras enreda besos entre sus palabras:...».

22 Un esclarecedor estudio del papel del relato y el significado de la figura de Orfeo en sus dos tratamientos canónicos en la literatura latina -en las Geórgicas de Virgilio y en Ovidio- ofrece M. von Albrecht (1995) y, más recientemente, Eigler (2012).

23 La misma temática de Venus y Adonis ilustra desde un cuadro en la pared otros óleos con «enfermas de amor» de Jan Steen ( $c f$. Fig.5 de la primera parte; $c f$. http://www.taftmuseum.org/collections/collection highlights/11-1931-396_tma-06-09 [26/03/2016]) y de otros artistas. Por otro lado, también es igualmente intencionada la elección de la otra temática mitológica presente desde el cuadro-dentro-del-cuadro en otra obra de Steen protagonizada por una «enferma de amor»: la de «la batalla de Centauros contra los lápitas», que simboliza el fracaso en el dominio de la voluntad y la claudicación ante el impulso de las más bajas pasiones ( $c f$. por ejemplo, https:/www.mauritshuis.nl/en/explore/the-collection/artworks/the-doctors-visit-168/\# [21/03/2016]); sobre este asunto preparo un estudio del que es anticipo mi comunicación «Los extravíos del ocio: el mal de amores y los excesos del vino. Un tema de tradición clásica en la pintura holandesa del Siglo de Oro», leída en el VIII Congreso de la SELat., León, del 29 de junio al 2 de julio de 2016. 
ha narrado por extenso en los versos inmediatamente anteriores del relato ovidiano (Met.10.298-502), y, a través de ella, el tema de la pasión irreprimible y del embarazo: Mirra, presa de una obcecación incestuosa hacia su padre Cíniras, logra consumarla gracias a la complicidad de la nodriza (como la arquetípica Fedra y como presumiblemente la dama enferma del cuadro). Ya la pulsión de esta irrefrenable pasión pecaminosa justificaría la mención que hago de la madre de Adonis, pero quiero destacar además la importancia que cobra en su relato el tema del embarazo fruto de este incesto, pues el poeta se complace en describir con detalle el trabajoso parto y milagroso nacimiento de Adonis, que cae desprendido a través de una hendidura en la corteza del árbol de la mirra en el que se ha transformado su madre (Met.10.503513). Y, como ya hemos visto, el tema del posible embarazo de la 'enferma de amor' está también sugerido en el cuadro.

El motivo del adulterio tampoco falta en el relato principal. Cuando Venus se enamora de Adonis, se dice que la diosa, cautivada por la belleza del joven, desatiende todos sus lugares de culto y templos (Met.10.529-532):

capta uiri forma non iam Cythereia curat

litora, non alto repetit Paphon aequore cinctam

piscosamque Cnidon grauidamue Amathunta metallis;

abstinet et caelo: caelo praefertur Adonis. ${ }^{24}$

Del mismo modo entre los peligros de la pasión ilícita en una mujer casada están no solo la desatención del hogar y la ruina de su familia, sino también, desde el punto de vista moral y religioso, el pecado capital de la lujuria (reléase bajo esta consideración el verso ovidiano «se aparta del cielo: y antes que el cielo prefiere a Adonis»): si una admonición moral trasciende de este tipo de cuadros sería precisamente esta, la de prevenir contra la tentación pecaminosa del romance adúltero ${ }^{25}$. El trágico fin de Adonis, según algunas tradiciones mitológicas, se debe al castigo por celos de Marte, el amante 'oficial' de Venus, o de su esposo, el cojitranco y poco agraciado Hefesto. En cualquier caso, Venus resulta ser una adúltera por su relación con el joven y hermoso Adonis.

Pero es más, justo en el momento de la narración que ilustra el cuadro colgado en la pared, Venus comienza a narrarle a su joven amante -en un relato-dentro-de-unrelato-dentro-de-un-relato- la historia de Atalanta e Hipómenes (Met.10.560-707), que la exégesis alegórica contemporánea interpretaba como la caída en tentación de una mujer virtuosa, o como un relato de castigo por el pecado de lujuria, o como ilustración de la venalidad propia de la mujer, incapaz de resistirse a la tentación de la riqueza (Brumble 1998, 39-40).

24 «Presa de la hermosura de un hombre, poco le importan ya (a la diosa) las costas de Citera, ni frecuenta Pafos, ceñida por un hondo mar o Cnido, la rica en peces, ni Amatunte, preñada de metales; se aparta incluso del Olimpo: y es que antes que el Olimpo prefiere a Adonis»».

25 En la anónima obra de emblemática amorosa, surgida bajo la estela de las de O. Vaenius, titulada Thronus Cupidinis (Amsterdam, 1620) una paráfrasis de estos mismos versos ovidianos explica la incompatibilidad entre el amor y la dignidad (bajo el lema 18. «Non conueniunt Majestas \& Amor») precisamente con una estampa muy parecida a la de Tempesta: en ella se representa el amor de Venus hacia el joven Adonis, merced al cual toda una diosa como ella se vio rebajada y obligada a entregarse a un simple mortal bajo el imperativo del deseo erótico y a compartir con él sus bajas aficiones, como la de la caza ( $c f$. http://emblems.let.uu.nl/repository/tc1620_archive/ TC0043.jpg [26/03/2016]). 
Teniendo en cuenta que el relato principal del que dependen los demás está en boca de Orfeo, prototipo de esposo fiel a la memoria de su esposa, los amores ilícitos o sacrílegos de Venus y Adonis, de Mirra y Cíniras y de Atalanta e Hipómenes -el primero de ellos representado, los otros dos evocados desde el cuadro-dentro-delcuadro- sirven de contrapunto al amor conyugal de Orfeo e ilustran dos aspectos de la heroína enferma de amor en su relación con el género masculino: por un lado, hemos de suponer que la joven, como la Venus del cuadro de la pared, disfruta de un amante y que también como Mirra, la madre de Adonis, posiblemente se ha dejado arrastrar por esta pasión ilícita a riesgo de quedar embarazada; por otro lado, quizás tiene un viejo marido al que, como sugiere una de las interpretaciones de la historia de Atalanta, se ha unido solo por su ventaja económica.

Todas estas sugerencias que proyecta la técnica del cuadro-dentro-del-cuadro me permiten afianzar la hipótesis de que el señor mayor situado al fondo de la escena debe ser el marido engañado por la joven adúltera, ajeno -como el doctor-a la verdadera naturaleza del mal de su esposa, y ocupado, como es su deber, de la administración de su patrimonio (o para más escarnio, quizás calculando la elevada minuta del inútil médico).

En todo caso, parece evidente el contraste entre el comportamiento virtuoso del marido y las circunstancias más que dudosas que rodean a su esposa, sobre todo si comparamos la escena con esta otra, contenida en otro emblema de Vaenius, perteneciente a sus Horatiana Emblemata (Amberes, 1612), con la que guarda una gran similitud (Fig.10): en ella se puede contemplar a una mujer casada, casi una enferma, víctima, en este caso, de otras debilidades del cuerpo (la bebida y la comida) -obsérvense los símbolos de la virtud rotos a los pies de su cama-, mientras que su marido en la cámara del fondo apura las horas de la noche entregado al estudio ${ }^{26}$.

Otra sugerencia interesante emanada del contexto del relato ovidiano representado en el cuadro de la pared se relaciona con el milagroso parto de Adonis. Cuando el recién nacido cae desprendido de la corteza del árbol producto de la metamorfosis de su madre Mirra, el poeta, para alabar su extraordinaria belleza, hace uso de un símil del ámbito del arte figurativo que no se le pudo escapar a la atención de un pintor como Steen familiarizado con la literatura clásica (Met.10.515-519):

\[ [\ldots] \text { qualia namque } \]
corpora nudorum tabula pinguntur Amorum,
talis erat, sed, ne faciat discrimina cultus,
aut huic adde leues, aut illis deme pharetras. ${ }^{27}$

Este llamativo símil artístico me hace pensar que el niño con el arco y las flechas a los pies de la dama enferma no es simplemente, como se suele decir, un crío

26 Coetáneamente Joven ante el espejo (ca. 1662) de Frans van Mieris (en Gemäldegalerie, Berlín: https://www. pubhist.com/w4537 [21/03/2016]) denuncia, como mínimo, la flaqueza femenina (en este caso, el vicio de la uanitas) de un modo similar: en primer plano, una bella mujer de generoso escote se contempla en un espejo mientras se ajusta un collar, asistida por una joven esclava negra que le ofrece un joyero, sobre la silla se apoya un elegante abrigo, como si la dama se estuviera acicalando para salir; mientras, en la habitación del fondo, su marido, ajeno a todo, estudia un voluminoso libro. Sobre la mesa descansa una sospechosa nota doblada que sugiere una mayor complejidad dramática.

27 «... Pues, como suelen pintar en los cuadros el cuerpo desnudo de los Amorcillos, así era (el niño), pero, para que su indumentaria no permita el distingo, o a aquellos quítales sus ligeras aljabas o añádeselas a este otro...». 


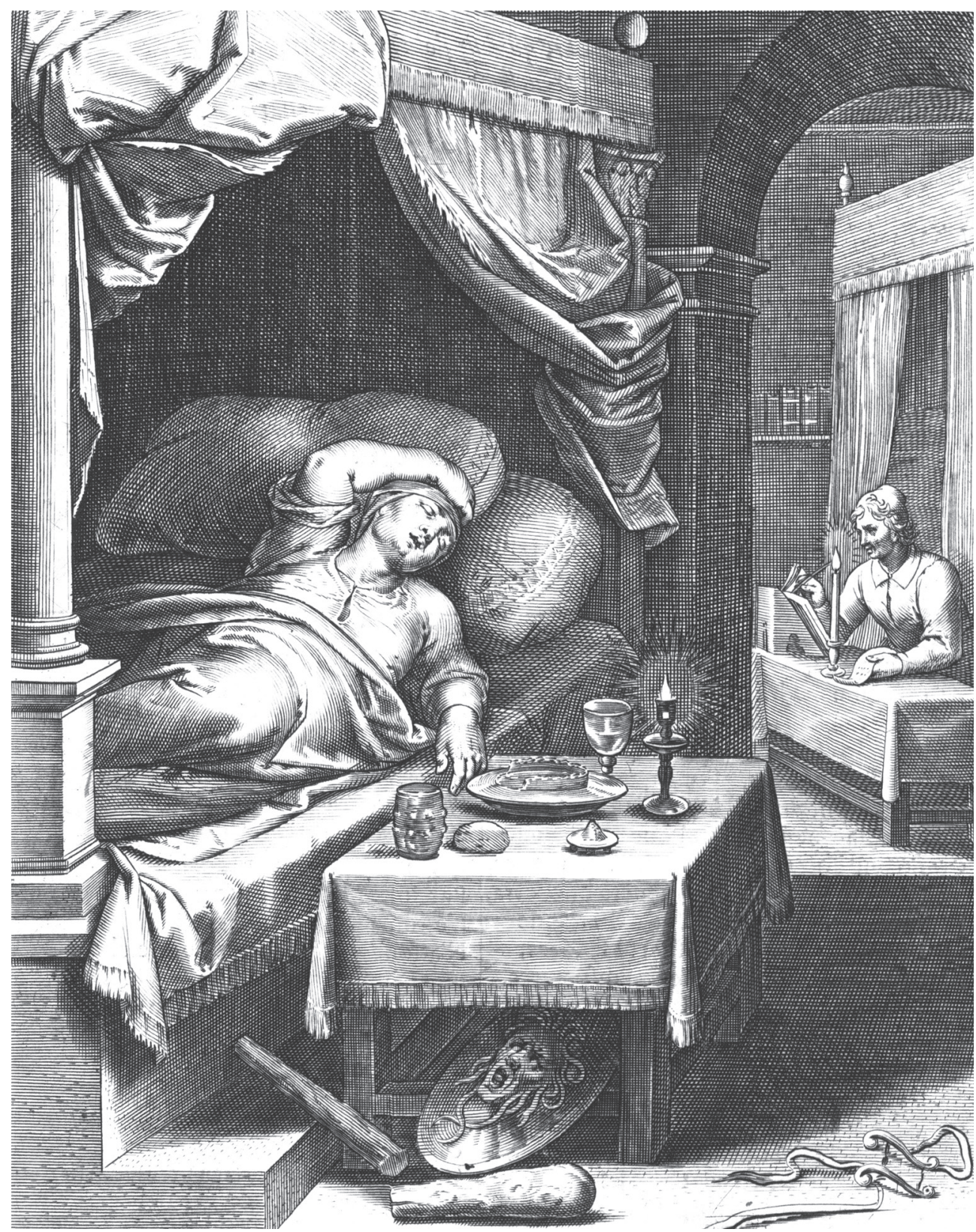

Fig. 10. Crapula ingenium offuscat (Emblema 17), Q.Horatii F. Emblemata (1612) de Otto Vaenius

jugando a ser Cupido. Más bien se trataría, como nos permite inferir el texto ovidiano relacionado con el cuadro-dentro-del-cuadro, de un niño que hace de Adonis con el carcaj de Cupido. En esta misma época otro pintor barroco holandés, Nicolaes Maes (1634-1693), posiblemente también con estos versos ovidianos en mente, realizaba retratos infantiles de «niños como Adonis» (Fig.11), niños, como el infante 


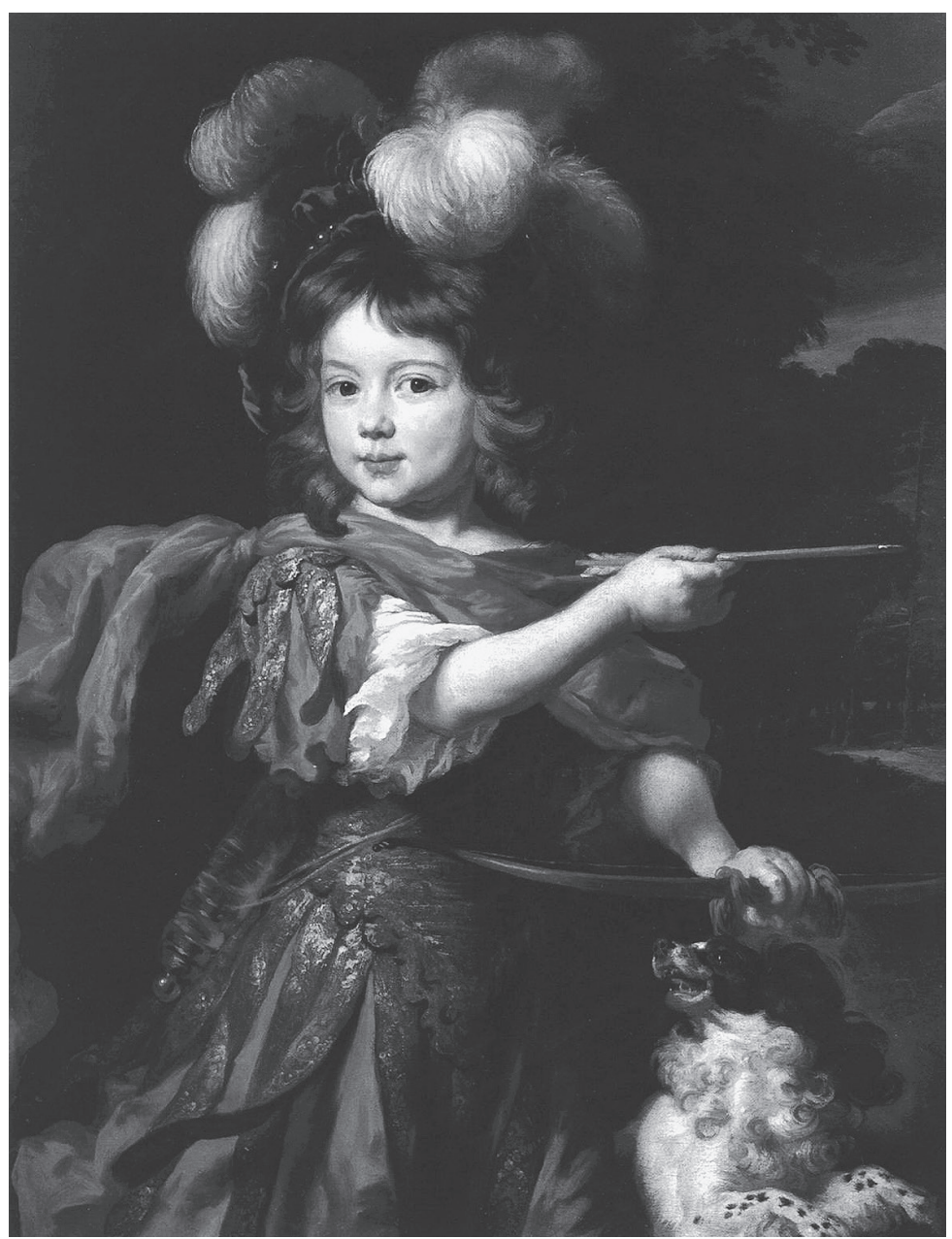

Fig. 11. Niño como Adonis (ca. 1670). Nicolaes Maes, Academy of Fine Arts, Viena

del cuadro de Steen, pertrechados de útiles cinegéticos y caracterizados como cazadores en ciernes.

De ser cierta esta última hipótesis, en el cuadro podríamos dibujar dos triángulos superpuestos y complementarios. Uno, obvio, el que conforman doctor, enferma y sirvienta/enfermera (que asiste al médico sosteniéndole la mátula) respondería al título genérico de «la visita del doctor». El otro, más sutil, sugerido por el texto ovidiano que se oculta en el cuadro-dentro-del-cuadro, apuntaría más bien al segundo título que recibe este tipo de obras, «la enferma de amor»: en los vértices de este segundo triángulo estarían la dama aquejada del mal de amores, que, como Venus, es adúltera; el viejo marido engañado se deja atisbar al fondo, como un Hefesto todavía ajeno a su deshonra; y desde el primer plano, nos interpela directamente a los ojos el niño, que es, a primera vista, imagen metafórica, por sus atributos, de Cupido (quien en el relato ovidiano, mientras besaba a su madre, la hiere accidentalmente con una 
de sus flechas provocando su enamoramiento de Adonis), pero que puede ser, al mismo tiempo, imagen del amante de la dama-Venus, en cuanto que también podría representar a un Adonis niño al que se le han añadido las leues pharetras de las que habla Ovidio.

\section{De la letra a la tela: conclusiones}

Como hemos podido comprobar, la pervivencia de temas y elementos de la literatura antigua a través de la tradición clásica rara vez es lineal y unidireccional; más bien opera por acumulación de una serie de indicios de distinta procedencia y muy variados estratos cronológicos que a través de numerosos vasos comunicantes conforman un vasto panorama cultural permeable a toda suerte de influjos.

En la iconografía de «la visita del médico», tema que se desarrolla en la pintura de género holandesa desde mediados del siglo XVII con Jan Steen como principal exponente (y que alcanzará a otros sectores del arte occidental hasta fines del siglo XIX), la influyente comedia contemporánea y el omnipresente género de la emblemática en la cultura holandesa de la época son, entre otros más, dos cauces privilegiados de recepción $\mathrm{y}$, a su vez, de transmisión de la tradición clásica por los que se tamizan e irradian numerosos elementos de la literatura grecolatina y sus herederas. Entre ellos destacan los relacionados con los conceptos interrelacionados del amor y de la naturaleza de la mujer y con la percepción literaria de la figura del médico desde la Antigüedad: elementos como la consideración del amor como una enfermedad diagnosticable a través de un catálogo siempre creciente de síntomas; el prejuicio misógino (médico, literario, mitológico, religioso y cultural) de la mujer como un sexo imperfecto, inferior y débil, fatalmente inclinado por ello a las debilidades de la carne y al amor; la sátira de costumbres; la tradicional falta de confianza en la ciencia médica, en sus representantes y en sus prácticas terapéuticas; la burla cómica del médico ampuloso, desfasado e incompetente; las posturas a favor o en contra de la posibilidad de curación del mal de amor; la imaginería asociada a Eros/Cupido, la intriga narrativa asociada al cortejo erótico y todos los elementos simbólicos y alegóricos vinculados al fenómeno amoroso (el poder de la música, la fiebre, el calor, etc).

Sin la correcta identificación, individualización e interpretación de cada uno de estos elementos se nos escapa la cabal intelección de la obra pictórica y corremos el riesgo de no calibrar en su justa medida la profunda huella que la tradición clásica ha imprimido a lo largo y ancho de la Historia del Arte. Interpretar correcta y plenamente el asunto de un lienzo surgido de un movimiento artístico tan complejo como el Barroco exige saber descifrar el aporte de significado que cada uno de estos signos iconográficos, que hunden sus raíces en la cultura grecorromana y no cesaron de desarrollarse durante la Edad Media y el Renacimiento, incorpora, de modo más o menos evidente o de modo más o menos velado, a la idea representada.

\section{Referencias bibliográficas}

Agudelo, P.A. (2011), «Los ojos de la palabra. La construcción del concepto de écfrasis, de la Retórica Antigua a la crítica literaria», Lingüistica y Literatura 60, 75-92. Albrecht, M. von (1995), «Orfeo en Virgilio y Ovidio», Myrtia 10, 17-33. 
Alciatus, Andrea (1531), ...Andreae Alciati... Emblematum liber, Augusta Vindelicorum, per Henricum Steynerum.

Barchesi, A. (2002), «Narrative Technique and Narratology in the Metamorphoses», en Hardie, Ph., The Cambridge Companion to Ovid, Cambridge, University Press, 180-199.

Barscht, Adam (1818), Le peintre graveur, Viena.

Baumbach, M. - Bär, S. (2012), Brill's Companion to Greek and Latin 'epyllyon' and its reception, Leiden - Boston, Brill.

Brian, Thomas (1637), The Pisse-prophet or certain Pisse-pot lectures, wherein are newly discovered the old fallacies, deceit, and jugling of the Pisspot Science, used by all those (wheter Quacks or Empiricks, or other methodical physicians) who pretend knowledg of Diseases, by the Urine, in giving judgement by the same, Londres.

Brumble, H.D. (1998), Classical Myths and Legends in the Middle Ages and Renaissance: A Dictionary of Allegorical Meanings, Westport, Connecticut, Greenwood Press.

Crump, M.M. (1931), The Epyllion from Theocritus to Ovid, Oxford, Blackwell.

Díaz Gito, M.A. (2016), «De la letra a la tela (I): Jan Steen y La visita del médico en la pintura holandesa del Siglo de Oro a la luz de la tradición clásica», Cuadernos de Filología Clásica. Estudios Latinos 36(1), 121-142. http://dx.doi.org/10.5209/rev_CFCL.2016. v36.n1.52547

Dixon, L.S. (1993), «Some Penetrating Insights: The Imagery of Enemas in Art», Art Journal $52,28-35$.

Dixon, L.S. (1995), Perilous Chastity. Women and Illness in Pre-Enlightment Art and Medicine, Ithaca - Londres, Cornell University Press.

Dixon, L.S. (2015), "Art and the myth of the "wandering womb"», Hektoen International: A Journal of Medical Humanities 7.1, revista online en http://hektoeninterna tional.org/index.php?option=com_content\&view=article\&id=1754 [21/03/2016].

Eigler, U. (2012), «The Tenth Book of Ovid's Metamorphoses as Orpheus' epyllion», en Baumbach, M. - Bär, S. (2012), Brill's Companion to Greek and Latin 'epyllyon' and its reception, Leiden - Boston, Brill, 355-368.

Elsner, J.R. (2002), «Introduction: The Genres of Ekphrasis», Ramus 31, 1-18.

Foreest, Pieter van (1589), De incerto, fallaci Urinarum judicio quod Uromantes ad perniciem multorum aegrotantium utuntur \& qualia illi sint observanda, tum praestanda, qui recte de urinis sit judicaturus, libri tres, per dialogismum contra Uroscopos concinnati. Lugduni Batavorum, ex officina Plantiniana.

Franits, W. (2004), Dutch seventeenth-century genre painting. Its stilistic and thematic evolution, New Haven - Londres, Yale University Press.

Hollis, A. (2006), «The Hellenistic Epyllion and its descendants», en Johnson, S.F. (ed.), Greek literature in late antiquity: dynamism, didacticism, classicism, Aldershot - Burlington, Ashgate Pub., 141-157.

Hörnigk, Ludwig von (1638), Politia medica Oder Beschreibung dessen was die Medici, so wohl insgemeins als auch auch verordnete Hof-Statt-Feldt-Hospital- und Pest-Medici etc, Frankfurt am Mann.

Hunter, R.L. (2004), «Epic in a Minor Key», en Fantuzzi, M. - Hunter, R. (eds), Tradition and Innovation in Hellenistic Poetry, Cambridge, Cambridge University Press, 191-245.

Joubert, F.E., El manuel de l'amateur d'estampes, París, 1821.

Lubsen-Brandsma, M.A.C. (1997), «Het veterpotje van Jan Steen; zwangerschapstest of gynaecologisch therapeuticum in de 17e eeuw?», Tijdschr Geneeskd 141, 2513-2517.

Mesa Sanz, J.F. (2010), «Rhetorum itinera: écfrasis», Eikasia. Revista de Filosofía 5(32), 173-196. 
Metamorphoseon, Sive Transformationum Ovidianarum Libri Quindecim, Aeneis Formis ab Antonio Tempesta Florentino Incisi, et in Pictorum Antiquitatisque Studiosorum Gratiam Nunc Primum Exquisitissimis Sumptibus a Petro de Iode Antuerpiano in Lucem Editi. Amsterdam, [1606?].

Owen Lee, M. (1996), Virgil as Orpheus: A Study of the Georgics, Nueva York, State University of Nueva York Press.

Panofsky, E. (1969), Problems on Titian: Mostly Iconographic, Londres, Phaidon.

Quevedo y Villegas, F. (1884), El gran tacaño. Visita de los chistes. Cuento de cuentos. La casa de los locos de amor. Libro de todas las cosas y otras muchas más. Pragmática del tiempo, Barcelona, Biblioteca Clásica Española.

Ripa, Cesare (1603), Iconologia overo descrittione dell'imagini universali cavate dall'antichità et da altri luoghi da Cesare Ripa perugino... Opera non meno utile, che necessaria à poeti, pittori, \& scultori, per rappresentare le virtù, vitii, affetti, \& passioni humane, Roma, Apresso Lepido Facii.

Scrobonius Wilhelm Adolph (1584), Idea Medicince secundum Logicas Leges informandae et describendce. Cui accessit De inspectione urinarum contra eos, qui ex qualibet urina de quolibet morbo judicare volunt etc. Lemgoviae.

Sklenáŕ, R. (2006), «How to Dress (for) an Epyllion: The Fabrics of Catullus 64», Hermes 134(4), 385-397.

Stolberg, M. (2015), Uroscopy in Early Modern Europe, Surrey, Ashgate.

Vaenius, Otho (1608), Amorum Emblemata figuris aeneis incisa studio Othonis Vaenii batavo-lugdunensis, Amberes.

Vaenius, Otho (1612), Quinti Horatii Flacci Emblemata, Amberes (=edición facsímil Universidad Europea de Madrid - CEES, Madrid, 1996). 